\title{
Current Medical and Surgical Management of Retained Lens Fragments After Cataract Extraction
}

\author{
Shlomit Schaal, MD, PhD, ${ }^{1}$ Brooke LW Nesmith, MD, JD, ${ }^{2}$ Mark A Ihnen, MD ${ }^{3}$ and Motasem Al-Latayfeh, MD ${ }^{4}$ \\ 1. Director of Retina, Director of Fellowship Programme in Vitreoretinal Diseases and Surgery, and Associate Professor; 2. Chief Resident; 3. Resident, Department of \\ Ophthalmology and Visual Sciences, University of Louisville School of Medicine, Kentucky, US; 4. Retina Specialist, Department of Ophthalmology, Faculty of Medicine,
}

Hashemite University, Amman, Jordan

\begin{abstract}
Purpose: To review current literature understanding and modern clinical guidelines, and to provide contemporary management recommendations regarding the medical and surgical management of retained lens fragments (RLF) after cataract surgery. Methods: Literature review for articles published in the PubMed database between 1948 and 2014 with the following keywords: retained lens fragments, retained lens material, dropped nuclear fragments, dislocated lens. Results: RLF is a complication of cataract surgery, with incidence reported between $0.18 \%$ and $1.1 \%$, which can result in severe inflammatory reaction, leading to significant vision-threatening complications, including cystoid macular edema, glaucoma, uveitis, and corneal edema. Management of RLF can be either medical or surgical, depending upon the severity of inflammation and symptoms. Proper timing of either medical or surgical management is crucial in preventing visual loss. Conclusion: RLF is a well-known complication of modern cataract surgery that should be managed promptly medically or surgically. Close cooperation between the anterior segment and posterior segment surgeon is crucial for optimal results.
\end{abstract}

\section{Keywords}

Retained lens fragments, cataract surgery

Disclosure: Shlomit Schaal, MD, PhD, Brooke LW Nesmith, MD, JD, Mark A Ihnen, MD, and Motasem Al-Latayfeh, MD, have no financial interests to declare.

Received: July 23, 2014 Accepted: August 28, 2014 Citation: US Ophthalmic Review, 2014;7(2):95-9 DOI: 10.17925/USOR.2014.07.02.95

Correspondence: Shlomit Schaal, MD, PhD, Department of Ophthalmology \& Visual Sciences, University of Louisville, 301 E Muhammad Ali Boulevard, Louisville, KY 40202.

E: s.schaal@|ouisville.edu

Support: The work was supported in part by an unrestricted grant from Research to Prevent Blindness, Inc. New York, New York, US.

Dislocation of lens fragments into the vitreous cavity is a rare, but potentially serious, complication of cataract surgery. Retained lens fragments (RLF) can result in a severe inflammatory reaction leading to significant vision threatening complications, including cystoid macular edema (CME), glaucoma, uveitis, and corneal edema. Proper timing of either medical or surgical management is crucial in preventing vision loss, and both anterior segment and vitreoretinal surgeons play an important role in the management of this serious condition.

\section{Incidence and Etiology}

The frequency of RLF after cataract surgery has been reported to vary from $0.18 \%$ to $1.1 \% .^{1-3}$ Factors affecting the incidence of RLF include surgeon's experience and surgical technique.2,4,5 The advent of modern phacoemulsification cataract surgery is associated with an increase in incidence of RLF, which may be related to surgical complexity and a steeper learning curve. ${ }^{6-8}$ In addition, certain types of cataract may be associated with increased risk for RLF, such as posterior polar cataracts and hard nuclear sclerotic cataracts. ${ }^{1,9}$

\section{Pathophysiology of Lens-induced Immune Response}

In its natural state, the anterior chamber of the eye is in a state of immune privilege. ${ }^{10}$ The lens proteins, or crystallins, are present in very low concentration within the anterior chamber. ${ }^{11}$ The immune system is tolerant to the lens proteins and these do not normally elicit an inflammatory reaction. This is achieved by the presence of immunoregulatory mechanisms within the anterior chamber, including cellular and humoral factors, which keep the immune reaction under control.10,12 The presence of RLF within the anterior chamber or the vitreous cavity induces an immediate autoimmune reaction to the lens proteins, which may vary depending on the size of the lens material, the duration of exposure, the individual immune response, and whether the lens material is cortex or nucleus. Although the exact mechanism of the RLF-induced immune response is incompletely understood, it is believed to be a T-cell-mediated delayed hypersensitivity reaction, with macrophages the predominant cell (see Figure 1). ${ }^{13,14}$ 
Figure 1: Lens-induced Immune Response

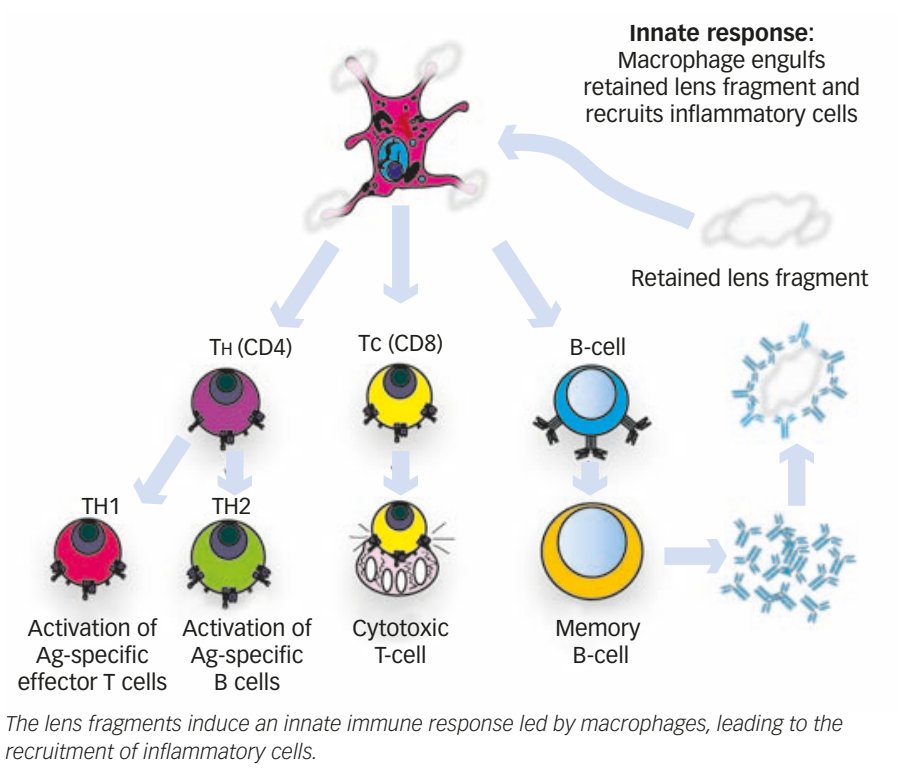

\section{Management of Retained Lens Fragments}

The ultimate goal of the management of RLF is to ensure stable, best-possible visual acuity. Vision loss after RLF may be related to the complications of $\mathrm{CME}$, severe uveitis, retinal detachment, or longstanding elevation of intraocular pressure. Depending upon the nature of the complications and the severity of induced inflammation, the management of RLF can be either surgical or medical. Schaal and Barr have suggested that RLF may be managed either medically or surgically. They retrospectively reviewed the cases of 42 patients with RLF after cataract surgery managed with either medical treatment or surgically with pars plana vitrectomy (PPV). ${ }^{15}$ In the case series, patients were divided into three groups: treatment with early PPV (less than 1 week after cataract surgery), treatment with late PPV (more than 1 week after cataract surgery), and treatment with medications alone. After 1 year, there was no statistically significant difference between the final visual acuity or intraocular pressure of the three groups, indicating no superiority of either treatment.

\section{Medical Management}

Some complications of RLF, depending upon their severity, may be managed with medical treatment alone.

\section{Cystoid Macular Edema}

CME is reported to occur after loss of lens material in up to $28 \%$ of RLF cases and is a significant cause of reduced visual acuity. ${ }^{6,15-17}$ Notably, CME occurs not only after complicated cataract surgery, but is also known to occur after uneventful phacoemulsification in about $2 \%$ of patients. ${ }^{18}$ In the case of RLF, two factors act synergistically to induce CME formation: surgically induced trauma and lens-induced uveitis. The diagnosis of CME is made clinically, and, with the recent advancement in imaging technology, optical coherence tomography (OCT) has become increasingly utilized in the diagnosis and management of CME, regardless of disease entity (see Figure 2). ${ }^{19,20} \mathrm{~A}$ recent study by Munk et al. ${ }^{21}$ proposed a classification for differentiation of macular edema based on its underlying pathology, using spectral domain OCT. The classification pattern was based on three parameters: microfoci, vertical macular edema pattern, and retinal nerve fiber layer, allowing for correct diagnosis of the underlying pathology in $84 \%$ of cases in the study. ${ }^{21}$ Established medical management of CME consists of topical nonsteroidal anti-inflammatory agents (NSAIDS).22-24 In addition, corticosteroids, either topical, periocular, or intravitreal, have also been shown to be effective in the treatment of $\mathrm{CME}$, and, in particular, in combination therapy with NSAIDs. ${ }^{23,25}$ More recently, the use of intravitreal bevacizumab and aflibercept for refractory CME has been shown to be effective..$^{26-28}$

\section{Glaucoma}

Secondary open-angle glaucoma has been reported to occur in over $50 \%$ of cases of RLF after cataract surgery. 9,17,29,30 The mechanism implicated in the elevation of intraocular pressure is outflow obstruction secondary to either the presence of macrophages and inflammatory mediators, or the precipitation of lens proteins in the trabecular meshwork. Medical management involves aggressive control of intraocular inflammation in addition to the use of pressure-lowering medications. Depending upon the severity of intraocular pressure elevation, a combination of different pressure-lowering agents may be necessary, as well as utilization of both topical and oral agents, such as acetazolamide.

\section{Uveitis}

Uveitis has been reported to vary in incidence from 30-87\% of RLF cases, with corticosteroids the mainstay of medical management. 8,9,31 The inflammatory response may be severe enough to mimic postoperative endophthalmitis, a complication that has also been associated with RLF. ${ }^{30,32}$ Negative bacteriology and the presence of RLF in the eye as visualized by ultrasound makes the diagnosis of RLF-related uveitis more likely. However, differentiation between uveitis and endophthalmitis secondary to RLF is not clinically obvious in a majority of cases, and early vitrectomy is prudent. ${ }^{32}$ The volume of RLF is associated with the intensity of the resulting intraocular inflammation., ${ }^{4,33}$ Smaller fragments, less than 5-10\% of total lens volume in one study, ${ }^{4}$ are associated with less inflammation. The type of material constituting the majority of the RLF is also a factor. Nuclear material is generally less tolerated, while those lens fragments that are predominantly cortex are resorbed more readily. $4,3,34$

\section{Corneal Edema}

corneal edema has been reported to occur in up to $51 \%$ of cases of RLFcomplicated cataract surgery. 6,17,35 The presence of uveitis and glaucoma leads to decompensation of the already-compromised endothelium by phacoemulsification. The goal of medical management is to recover endothelial function, resulting in the resolution of edema, by controlling inflammation and intraocular pressure as described previously., 47,35

\section{Retinal Detachment}

The incidence of retinal detachment in cases of RLF after cataract surgery varies widely between different studies, ranging from 4.8-45 \%.31,36,37 The reported incidence of retinal detachment increased in cases where the anterior segment surgeon manipulated the dropped lens fragments while attempting removal from the vitreous cavity. ${ }^{38-40}$ Management of retinal detachment is surgical and should be performed by a vitreoretinal surgeon.

\section{Other Complications}

Other reported complications in the literature include vitreous hemorrhage, ${ }^{6,41}$ lens fragments in the anterior chamber with recurrent 
Figure 2: Cystoid Macular Edema as Imaged on Optical Coherence Tomography Before and After Treatment
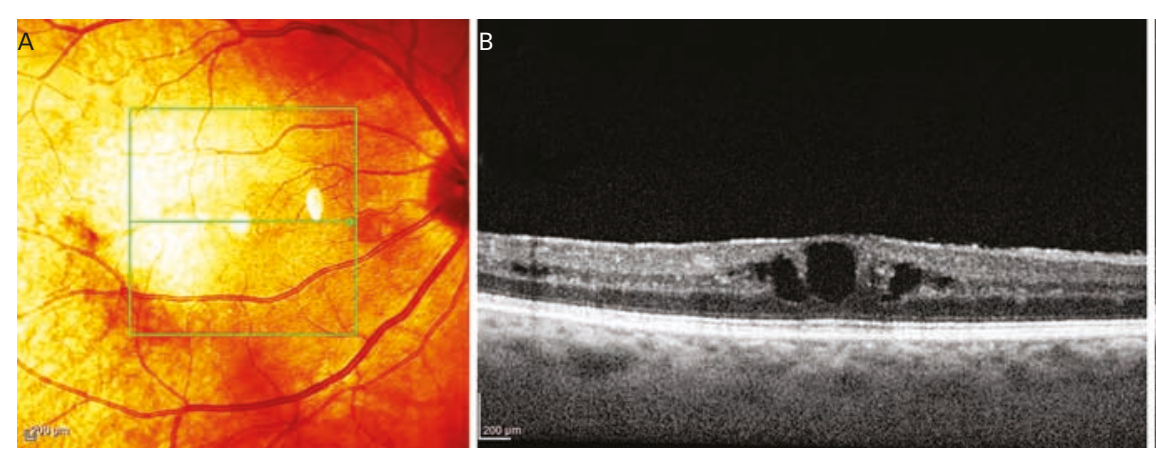

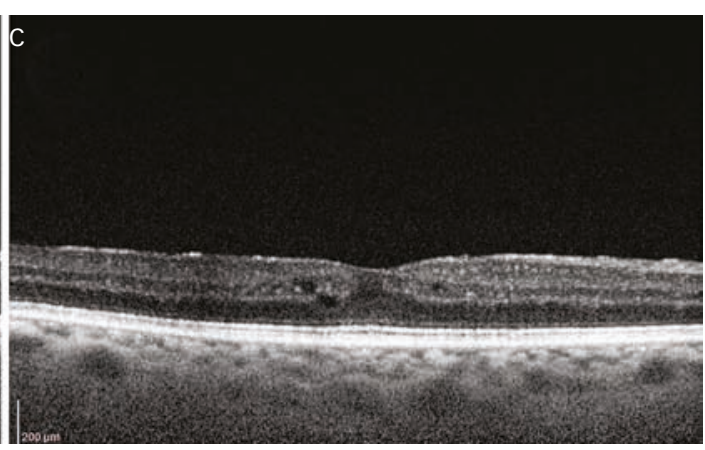

anterior uveitis, ${ }^{42}$ and retained lens material behind the iris presenting as an iris mass. ${ }^{43}$

\section{Surgical Management}

Although there are currently no guidelines for which patients should receive medical management or surgical management for RLF after cataract surgery, worsening visual acuity, or refractory response to medical management, including persistently elevated intraocular pressure or markedly severe inflammation, should warrant PPV..$^{15,39}$ Initially, however, in all cases of RLF, management begins with the anterior segment surgeon.

\section{Intraoperative Management by Anterior Segment Surgeon}

After dislocation of lens material into the vitreous cavity has occurred, the goal of the anterior segment surgeon should be to safely finish the case with minimal damage to ocular structures while maintaining good media clarity. Tight wound closure should be achieved, ensuring no vitreous is incarcerated in the surgical incision, followed by prompt referral of the patient to a vitreoretinal surgeon for further management. ${ }^{33,44}$ The implantation of an intraocular lens at the time of cataract surgery may be associated with better visual outcome. ${ }^{8,30}$ various techniques have been described in which the lens particles are manipulated by the anterior segment surgeon in an attempt to displace them into the anterior chamber. These techniques include direct fishing for the lenticular pieces, floating of the lens matter into the anterior chamber by infusing either saline or perfluorocarbons behind the lens through a pars plana approach, and posterior levitation of the lens using a spatula that pushes the lens forward through a pars plana incision..$^{39}$ Although there are reports in the literature on the safety of these procedures, ${ }^{45}$ all of these techniques are regarded as risky approaches by vitreoretinal surgeons due to the increased risk for vitreoretinal traction leading to subsequent giant tear formation and complex retinal detachment. ${ }^{38,39,46}$ From a vitreoretinal surgeon's point of view, manipulation of the lens after dislocation of lens material into the vitreous cavity should be minimized. Table 1 summarizes the role of the anterior segment surgeon in RLF cases.

\section{Timing of Pars Plana Vitrectomy}

There is no current consensus on the timing in which to undertake vitrectomy for the removal of RLF. In their study, Schaal and Barr did not demonstrate a difference in the final visual acuity and intraocular pressure after 1 year between those who underwent early vitrectomy (less than one week status post cataract surgery) and those who underwent late vitrectomy (more than one week status post cataract surgery). ${ }^{15}$ Other
Table 1: Recommendations for Management of Retained Lens Fragment by the Anterior Segment Surgeon

- Identify possible risk factors

- Choose the proper type of anesthesia and the appropriate surgeon's level of experience

- Identify posterior capsular tears promptly

- Maintain anterior chamber

- Minimize vitreous prolapse and perform anterior vitrectomy if needed

- Do not attempt to remove lens matter from vitreous cavity

- Insert an intraocular lens if possible

- Conclude the case with minimum ocular damage and good media clarity

- Refer the patient to vitreoretinal surgeon

\section{Figure 3: Vitrectomy for Retained Lens Fragments}

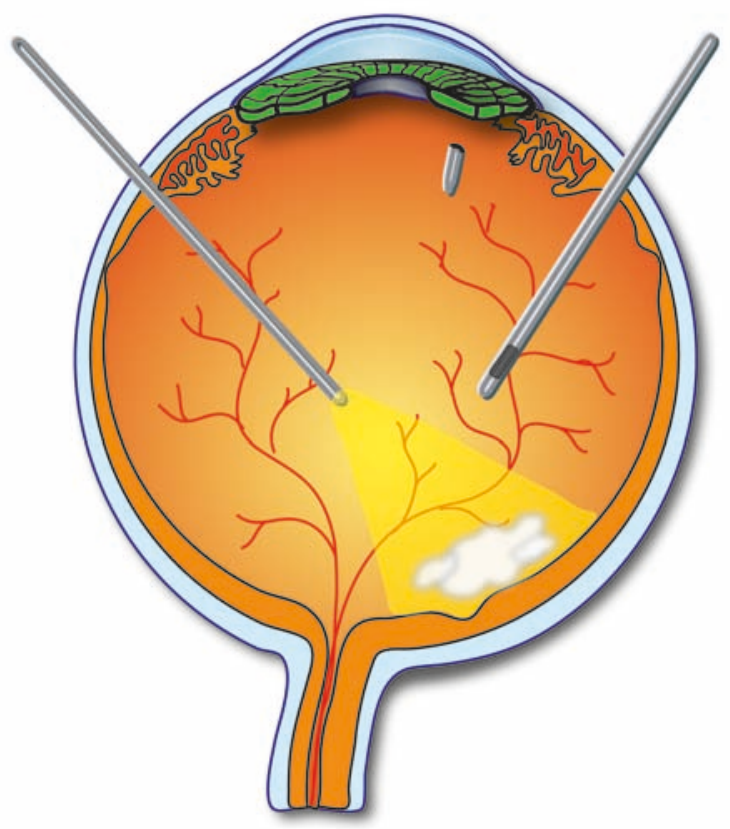

studies are in agreement and did not find any relationship between the timing of vitrectomy and final visual outcome. ${ }^{30,31,36,47-51}$ However, some studies suggest that vitrectomy undertaken at the time of cataract surgery (if a vitreoretinal surgeon is available) or within 3 weeks, may improve overall visual outcome and reduce the risk for chronic elevation of intraocular pressure. ${ }^{52-54}$ One systematic review and meta-analysis 
of retrospective interventional case series found optimal timing for vitrectomy in cases not requiring early PPV (i.e., in cases involving retinal detachment or endophthalmitis) to be between days 3 to 7 following cataract surgery. ${ }^{55} \mathrm{~A}$ significant association between retinal detachment and PPV performed more than 30 days after cataract surgery has also been shown. ${ }^{56}$ In common among these retrospective studies is the tendency to operate earlier on those eyes with severe intraocular inflammation.

\section{Choice of Vitrectomy Gauge}

Standard three-port 20-gauge PPV and ultrasonic fragmentation is an established surgical technique effective in removing RLF (see Figure 3). $4,17,47,56,57$ Following the development of small incision transconjunctival sutureless vitrectomy and its increased use in the surgical management of various vitreoretinal diseases, the safety and efficacy of 23-and 25-gauge PPV in removing RLF have been reported. ${ }^{58-64}$

The proposed advantages of using small gauge sutureless vitrectomy over standard 20-gauge PPV include less postoperative patient discomfort, reduced intraocular inflammation, and decreased mean operative times. ${ }^{65-67}$ These benefits, however, may potentially be dampened or lost if the RLF are too large or dense to completely and efficiently remove with a small gauge system. Thus, to aid in the removal of lens material, there is the need for the enlargement of one sclerotomy for the use of 20-gauge ultrasonic fragmentation. In addition, this results in longer surgical time, so it is often not a practical surgical approach for removing RLF.

As for complications, studies are not consistent in whether the use of ultrasonic fragmatome is associated with increased risk for retinal detachment and poor visual outcome. ${ }^{30,35,36,47,48,68}$ Furthermore, the need for 20-gauge ultrasonic fragmentation in small gauge vitrectomy cases is not consistent. Kiss and Vavvas, ${ }^{62}$ in their retrospective case series of six patients undergoing 25-gauge PPV for retained lens materials, described three out of six (50\%) as having a substantial portion of the nuclear material retained. Those patients required the use of 20-gauge ultrasonic fragmentation. ${ }^{62}$ However, Ho et al., ${ }^{61}$ in a retrospective case series of 17 patients with RLF, did not require fragmatome, only 25-gauge PPV, and those patients had RLF ranging from only cortex material to whole lens. As noted by the authors, these differences in need for 20-gauge fragmatome may be attributable to differences between vitrectomy systems, and thus vitreous cutters. ${ }^{61}$ In another study where 23-gauge PPV was used for the removal of dislocated lenses, the authors used perfluorocarbon liquid to fill the vitreous cavity and float the dislocated lens at the iris plane, where a phacomachine was then used to remove the lens. ${ }^{69}$ This technique eliminated the need for the use of 20-gauge fragmatome. Further known complications of small gauge vitrectomy, which may be seen after PPV for removal of RLF, include hypotony and choroidal effusion. ${ }^{67}$

Other considerations when choosing vitrectomy gauge for the removal of RLF include infusion and aspiration pressures. Due to the physics of smaller gauge instruments, higher infusion and aspiration pressures are needed to remove the retained lens particles using smaller probes such as 25-gauge probes. Even with increasing infusion and aspiration, as well as low cutting rate with core duty cycle, small gauge removal of particles may be time-consuming and quite tedious.

\section{Outcome of Vitrectomy for Retained Lens Fragments}

Vitrectomy for RLF is associated with improved visual acuity and reduction of intraocular inflammation and pressure, with $44-83 \%$ of patients achieving 20/40 or better visual acuity. 8,7,30,33,49,56 In a multivariate analysis of possible predictive factors of poor visual outcome $(\geq 20 / 200)$ following PPV for RLF, the following were shown to be of importance: absence of anterior vitrectomy at the time of cataract surgery, absence of sulcus lens, preexisting eye disease, and development of glaucoma. ${ }^{30}$ Vitrectomy for RLF has been associated with several postoperative complications, including glaucoma (2-25\%), CME (3-27\%), and retinal detachment (5.5-11.5 \%). 6,36-38,47,70 Prophylactic intraoperative $360^{\circ}$ laser retinopexy has been shown to be effective in reducing the rate of postoperative retinal detachment following vitrectomy. ${ }^{71}$ In addition, patients with a history of RLF following cataract surgery may develop delayed visual loss, thus longterm follow up is recommended. ${ }^{41}$

\section{Conclusion}

RLF is an uncommon but serious complication of cataract surgery, with clinical complications including CME, uveitis, glaucoma, corneal edema, and retinal detachment. Medical management is appropriate in certain cases, although depending upon the severity of inflammation and complications, surgical management may be necessary. As modern vitrectomy surgery techniques advance, the tendency to surgically intervene early in the management of RLF seems appropriate. Proper care of these patients to ensure best possible visual outcome involves good collaboration between the anterior segment surgeon and vitreoretinal surgeon.
1. Aasuri MK, Kompella VB, Majji AB, Risk factors for and management of dropped nucleus during phacoemulsification, I Cataract Refract Surg, 2001;27:1428-32.

2. Pande $M$, Dabbs TR, Incidence of lens matter dislocation during phacoemulsification, I Cataract Refract Surg, 1996;22:737-42.

. Jaycock P, Johnston RL, Taylor $\mathrm{H}$, et al., The Cataract National Dataset electronic multi-centre audit of 55,567 operations: updating benchmark standards of care in the United Kingdom and internationally, Eye (Lond), 2009:23:38-49.

4. Monshizadeh R, Samiy N, Haimovici R, Management of retained intravitreal lens fragments after cataract surgery, Surv Ophthalmol, 1999;43:397-404

5. Ti SE, Yang YN, Lang SS, Chee SP, A five-year audit of cataract surgery outcomes after posterior capsule rupture and risk factors affecting visual acuity, Am J Ophthalmol, 2014:157:180-5.

6. Gilliland GD, Hutton WL, Fuller DG, Retained intravitreal lens fragments after cataract surgery, Ophthalmology, 1992;99:12637: discussion 1268-9.

7. Stilma JS, van der Sluijs FA, van Meurs JC, Mertens DA, Occurrence of retained lens fragments after phacoemulsification in the Netherlands, $J$ Cataract Refract surg 1997;23:1177-82

8. Kim JE, Flynn HW Jr, Smiddy WE, et al. Retained lens fragments after phacoemulsification, Ophthalmology, 1994;101:1827-32.
9. Romero-Aroca P, Fernandez-Ballart J, Mendez-Marin I, et al., Management of nucleus loss into the vitreous: Iong term follow up in 63 patients, Clin Ophthalmol, 2007;1:505-12.

10. Streilein JW, Ocular immune privilege: the eye takes a dim but practical view of immunity and inflammation, I Leukoc Biol, 2003;74:179-85.

11. Sandberg $\mathrm{HO}$, Closs $\mathrm{O}$, The alpha and gamma crystallin conten in aqueous humor of eyes with clear lenses and with cataracts, Exp Eye Res, 1979:28:601-10.

12. Taylor AW, Kaplan HJ, Ocular immune privilege in the year 2010 : ocular immune privilege and uveitis, Ocul Immunol Inflamm, 2010;18:488-92.

13. Wilkinson $\mathrm{CP}$, Green WR, Vitrectomy for retained lens material after cataract extraction: the relationship between histopathologic findings and the time of vitreous surgery, Ophthalmology, 2001:108:1633-7.

14. Marak GE Ir, Phacoanaphylactic endophthalmitis, Surv Ophthalmol, 1992:36:325-39.

15. Schaal S, Barr CC, Management of retained lens fragments after cataract surgery with and without pars plana vitrectomy, J Cataract Refract Surg, 2009;35:863-7.

16. Cohen SM, Davis A, Cukrowski C, Cystoid macular edema after pars plana vitrectomy for retained lens fragments, I Cataract Refract Surg, 2006;32:1521-6.
17. Margherio RR, Margherio AR, Pendergast SD et al, Vitrectomy for retained lens fragments after phacoemulsification Ophthalmology, 1997;104:1426-32

18. Stark WJ Jr, Maumenee AE, Fagadau W, et al., Cystoid macular edema in pseudophakia, Surv Ophthalmol, 1984;28(Suppl):442-51.

19. Baskin $D E$, Optical coherence tomography in diabetic macular edema, Curr Opin Ophthalmol, 2010;21:172-177.

20. Minnella AM, Savastano MC, Zinzanella G, et al., Spectradomain optical coherence tomography in Irvine-Gass syndrome, Retina, 2012;32:581-7.

21. Munk MR, Sacu S, Huf W, et al., Differential diagnosis of macular edema of different pathophysiologic origins by spectral domain optical choherence tomography, Retina, 2014 [ePub ahead of print].

22. Warren KA, Fox JE, Topical nepafenac as an alternate treatment for cystoid macular edema in steroid responsive patients, Retina, 2008:28:1427-34.

23. Shelsta HN, Jampol LM, Pharmacologic therapy of pseudophakic cystoid macular edema: 2010 update, Retina, 2011;31:4-12.

24. Rossetti L, Chaudhuri J, Dickersin K, Medical prophylaxis and treatment of cystoid macular edema after cataract surgery. The results of a meta-analysis, Ophthalmology, 1998:105:397-405.

25. Warren KA, Bahrani H, Fox JE, NSAIDS in combination therapy 
for the treatment of chronic pseudophakic cystoid macular edema, Retina, 2010;30:260-6.

26. Barone A, Russo V, Prascina F, Delle Noci N, Short-term safety and efficacy of intravitreal bevacizumab for pseudophakic cystoid macular edema, Retina, 2009;29:33-7.

27. Ghasemi Falavarjani K, Parvaresh MM, Modarres M, et al., Intravitreal bevacizumab for pseudophakic cystoid macular edema; a systematic review, J Ophthalmic Vis Res, 2012;7:235-9.

28. Eadie JA, I I MS, Kulkarni AD, Response to aflibercept as secondary therapy in patients with persistent retinal edema due to central retinal vein occlusion intially treated with bevacizumab or ranibizumab, Retina, 2014 [ePub ahead of print].

29. Tommila P, Immonen I, Dislocated nuclear fragments after cataract surgery, Eye (Lond), 1995;9(Pt 4):437-41.

30. Ho LY, Doft BH, Wang L, Bunker CH, Clinical predictors and outcomes of pars plana vitrectomy for retained lens materia after cataract extraction, Am J Ophthalmol, 2009;147:587-94 e581.

31. Ho SF, Zaman A, Clinical features and outcomes of pars plana vitrectomy in patients with retained lens fragments after phacoemulsification, I Cataract Refract Surg, 2007;33:2106-10.

32. Kim JE, Flynn HW Jr, Rubsamen PE, et al., Endophthalmitis in patients with retained lens fragments after phacoemulsification, Ophthalmology, 1996;103:575-8.

33. Rofagha S, Bhisitkul RB, Management of retained lens fragments in complicated cataract surgery, Curr Opin Ophthalmol, 2011;22:137-40.

34. Moisseiev E, Kinori M, Glovinsky Y, et al.,Retained lens fragments: nucleus fragments are associated with worse prognosis than cortex or epinucleus fragments, Eur Ophthalmol, 2011;21:741-7.

35. Oruc S, Kaplan HJ, Outcome of vitrectomy for retained lens ragments after phacoemulsification, Ocul Immunol Inflamm 2001;9:41-7.

36. Scott IU, Flynn HW Jr, Smiddy WE, et al.. Clinical features and outcomes of pars plana vitrectomy in patients with retained lens fragments, Ophthalmology, 2003;110:1567-72.

37. Moore JK, Scott IU, Flynn HW Jr, et al., Retinal detachment in eyes undergoing pars plana vitrectomy for removal of retained lens fragments, Ophthalmology, 2003;110:709-13; discussion 713-4.

38. Olsson RB, Ritland JS, Bjornsson OM, et al., A retrospective study of patients with retained nuclear fragments after cataract extraction, Acta Ophthalmol Scand, 2000;78:677-9.

39. Stewart MW, Managing retained lens fragments: raising the bar, Am J Ophthalmol, 2009;147:569-70.

40. Kim IK, Miller JW, Management of dislocated lens material, Semin Ophthalmol, 2002;17:162-6.
41. Greven CM, Piccione K, Delayed visual loss after pars plana vitrectomy for retained lens fragments, Retina, 2004;24:363-7.

42. Teo L, Chee SP, Retained lens fragment in the anterior segment as a cause of recurrent anterioruveitis, Int Ophthalmol, 2010;30:89-91.

43. Olsen TW, Lim Jl, Grossniklaus HE, Retained lens material masquerading as a growing, pigmented iris tumor, Arch Ophthalmol, 1996;114:1154-5.

44. Karadag R, Aydin B, Management of the dropped nuclear fragments, Br J Ophthalmol, 2013;97:2-4

45. Schutz JS, Mavrakanas NA, Posterior-assisted levitation in cataract surgery, Curr Opin Ophthalmol, 2010;21:50-4.

46. Arbisser LB, Charles S, Howcroft M, Werner L, Management of vitreous loss and dropped nucleus during cataract surgery, Ophthalmol Clin North Am, 2006;19:495-506.

47. Borne MJ, Tasman W, Regillo C, et al., Outcomes of vitrectomy for retained lens fragments, Ophthalmology, 1996;103:971-6.

48. Orlin A, Parlitsis G, Chiu YL, et al., A comparison of same setting versus delayed vitrectomy in the management of retained lens fragments after cataract surgery, Retina, 2014 lePub ahead of print].

49. Modi YS, Epstein A, Smiddy WE, et al., Retained lens fragments after cataract surgery: outcomes of same-day versus later pars plana vitrectomy, Am J Ophthalmol, 2013;156:454-9 e451.

50. Vanner EA, Stewart MW, Liesegang TJ, et al., A retrospective cohort study of clinical outcomes for intravitreal crystalline retained lens fragments after age-related cataract surgery: a comparison of same-day versus delayed vitrectomy, Clin ophthalmol, 2012;6:1135-48.

51. Colyer MH, Berinstein DM, Khan NJ, et al., Same-day versus delayed vitrectomy with lensectomy for the management of retained lens fragments, Retina, 2011;31:1534-40.

52. Kageyama T, Ayaki M, Ogasawara M, et al., Results of vitrectomy performed at the time of phacoemulsification complicated by intravitreal lens fragments, Br J Ophthalmol, 2001:85:1038-40.

53. Soliman Mahdy M, Eid MZ, Shalaby KA, Hegazy HM Intravitreal phacoemulsification with pars plana vitrectomy for management of posteriorly dislocated nucleus or lens fragments, Eur J Ophthalmol, 2010;20:115-9.

54. Stefaniotou M, Aspiotis M, Pappa C, et al., Timing of dislocated nuclear fragment management after cataract surgery, I Cataract Refract Surg, 2003;29:1985-8

55. Vanner EA, Stewart MW, Vitrectomy timing for retained lens fragments after surgery for age-related cataracts: a systematic review and meta-analysis, Am J Ophthalmol, 2011:152:345-57 e343.

56. Merani R, Hunyor AP, Playfair TJ, et al., Pars plana vitrectomy for the management of retained lens material after cataract surgery, Am J Ophthalmol, 2007:144:364-70.
57. Vilar NF, Flynn HW Jr, Smiddy WE, et al., Removal of retained lens fragments after phacoemulsification reverses secondary glaucoma and restores visual acuity, Ophthalmology, 1997;104:787-91; discussion 791-82.

58. Horozoglu F, Yanyali A, Macin A, et al., 23-gauge transconjunctival sutureless vitrectomy for retained len fragments after complicated cataract surgery, Retina, 2012;32:493-8.

59. Cho M, Chan RP, 23-gauge pars plana vitrectomy for management of posteriorly dislocated crystalline lens, Clin Ophthalmol, 2011:5:1737-43.

60. Baker PS, Spirn MJ, Chiang A, et al., 23-gauge transconjunctival pars plana vitrectomy for removal of retained lens fragments, Am J Ophthalmol, 2011;152:624-7.

61. Ho LY, Walsh MK, Hassan TS, 25-gauge pars plana vitrectomy for retained lens fragments, Retina, 2010;30:843-9.

62. Kiss S, Vavvas D, 25-gauge transconjunctival sutureless pars plana vitrectomy for the removal of retained lens fragments and intraocular foreign bodies, Retina, 2008:28:1346-51.

63. Barthelmes D, Alexander S, Mitchell P. Chandra J, Hybrid 20/23-gauge pars plana vitrectomy for retained lens fragments after cataract surgery, Retina, 2012;32:1749-55.

64. Bhandari R, Ernst BJ, Stafeeva K, et al., 23-gauge vitrectomy for retained lens material, Ophthalmic Surg Lasers Imaging 2012;43:351-2.

65. Inoue $\mathrm{Y}$, Kadonosono $\mathrm{K}$, Yamakawa T, et al., Surgically-induced inflammation with 20-, 23-, and 25-gauge vitrectomy systems: an experimental study Retina, 2009:29:477-80.

66. Fujii GY, De Juan E Jr, Humayun MS, et al., Initial experience using the transconjunctival sutureless vitrectomy system fo vitreoretinal surgery, Ophthalmology, 2002;109:1814-20.

67. Thompson JT, Advantages and limitations of small gauge vitrectomy, Surv Ophthalmol, 2011;56:162-72.

68. Al-Khaier A, Wong $\mathrm{D}$, Lois $\mathrm{N}$, et al., Determinants of visual outcome after pars plana vitrectomy for posteriorly dislocated lens fragments in phacoemulsification, J Cataract Refract Surg, 2001:27:1199-1206

69. Jang HD, Lee SJ, Park JM, Phacoemulsification with perfluorocarbon liquid using a 23-gauge transconjunctival sutureless vitrectomy for the management of dislocated crystalline lenses, Graefes Arch Clin Exp Ophthalmol, 2013;251:1267-72.

70. Salam GA, Greene JM, Deramo VA, et al., Retinal tears and retinal detachment as factors affecting visual outcome after cataract extraction complicated by posteriorly dislocated lens material, Retina, 2005;25:570-5.

71. Koh HJ, Cheng L, Kosobucki B, Freeman WR, Prophylactic intraoperative 360 degrees laser retinopexy for prevention of retinal detachment, Retina, 2007;27:744-9. 